\title{
ADAPTAÇÃO DE CONTO DE FADAS PARA O CINEMA E A FORMAÇÃO DO LEITOR: UMA ESTRATÉGIA DE LEITURA DE A BELA ADORMECIDA E MALEFICENT
}

\author{
FAIRY TALE ADAPTATION FOR THE CINEMA AND THE \\ TRAINING OF THE READER: A READY STRATEGY FOR THE \\ SLEEPING BEAUTY AND MALEFICENT
}

Deisi Luzia Zanatta*

\begin{abstract}
Resumo: Os contos de fadas marcaram fortemente a infância de muitas crianças. Nos dias atuais, algumas adaptações dessas histórias apresentam uma nova roupagem para tais narrativas. Este artigo tem por objetivo discutir o conto de fadas A bela adormecida e o filme Maleficent e apresentar uma estratégia de leitura de ambas as narrativas para a formação de leitores na Educação Básica. Para tal, buscamos auxílio teórico em Diana e Mário Corso (2005, 2014), Wolfgang Iser (1999), Bruno Bettelheim (1980), Peter Hunt (2010) e Jorge Larossa (2003). Este estudo evidenciou que o desenvolvimento de ações metodológicas de leitura que possibilitam o trabalho com histórias clássicas e suas adaptações contemporâneas como o conto A Bela Adormecida e Maleficent se faz relevante para auxiliar os sujeitos na compreensão de si e do mundo e, principalmente, a partir disso, tornarem-se cidadãos críticos.

Palavras-chave: Conto de fadas. A Bela Adormecida. Maleficent. Estratégia de leitura. Formação do leitor.
\end{abstract}

\begin{abstract}
Fairy tales have strongly marked the childhood of many children. Today, some adaptations of these stories present a new guise for such narratives. This article aims to discuss the fairy tale The Sleeping Beauty and the Maleficent film and present a strategy of reading both narratives for the formation of readers in Basic Education. For this, we are looking for theoretical help in Diana and Mário Corso (2005, 2014), Wolfgang Iser (1999), Bruno Bettelheim (1980), Peter Hunt (2010) and Jorge Larossa (2003). This study showed that the development of methodological actions of reading that make possible the work with these classic histories and their contemporary adaptations like the story Sleeping Beauty and Maleficent it relevant to help the subjects in the understanding of themselves and the world and, especially, the from this, become critical citizens.
\end{abstract}

Keywords: Fairy tale. Sleeping Beauty. Maleficent. Reading strategy. Formation of the reader.

\section{Introdução}

Os contos de fadas e suas adaptações contemporâneas para o cinema merecem uma atenção significativa nos estudos voltados para a área da Literatura, pois ao entrar em contato com essas histórias, a criança pode identificar situações por ela vivenciadas ao articular as ações das personagens ficcionais com as suas necessidades interiores.

Com isso, neste trabalho, fazemos uma abordagem do conto de fadas A Bela Adormecida, dos Irmãos Grimm e o filme Maleficent e apresentamos uma estratégia de leitura de ambas as narrativas para a formação de leitores na infância. Tal estudo se justifica pelo fato de os contos de fadas, na maioria das vezes, serem o primeiro contato das crianças com os textos e exercerem forte influência na constituição como leitores.

\footnotetext{
* Doutora em Letras pela Universidade de Passo Fundo (UPF). Professora Tutora On-line da Católica de Santa Catarina - Centro Universitário, de Jaraguá do Sul - SC. E-mail: deisil.zanatta@ gmail.com
} 
Também, usamos como argumento o fato dessas histórias apresentarem temáticas importantes para a formação do pensamento crítico do receptor.

Diante desse contexto, levando em consideração que a linguagem é composição fundamental da literatura e da cultura, consequentemente, componente imprescindível nas práticas leitoras, buscamos auxílio teórico para a reflexão proposta neste trabalho em Diana e Mário Corso $(2005,2014)$ sobre a psicanálise nas histórias infantis, Wolfgang Iser (1999) sobre a Teoria da Recepção, Bruno Bettelheim (1980) acerca da psicanálise nos contos de fadas, em Peter Hunt (2010) sobre o leitor e o sentido e em Jorge Larossa (2003) sobre a experiência da leitura.

Assim, o presente trabalho está estruturado da seguinte maneira para além da introdução: em primeiro, algumas concepções teóricas; na sequência, apresentamos o enredo do conto de fadas A Bela Adormecida e do filme Maleficent, uma estratégia de leitura para a Educação Básica com o conto dos Irmãos Grimm e a narrativa cinematográfica e por fim, as considerações finais.

\section{Abordagens teóricas acerca da teoria da recepção e da leitura}

Segundo Wolfgang Iser (1999), o estudo de uma obra literária não pode ser considerado apenas em relação à estrutura do texto, mas também pelos atos de sua recepção. Para o teórico, há a recepção e o efeito. A recepção é a assimilação documentada de textos e é, por conseguinte, extremamente dependente de testemunhos, nos quais atitudes e reações se manifestam enquanto fatores que condicionam a apreensão de textos. Já o efeito do texto é a "prefiguração da recepção", tendo com isso um potencial de efeito cujas estruturas põem a assimilação em curso e a controlam até certo ponto. Nesse sentido, no auge da estética da recepção, efeito e recepção se cruzam fazendo com que a arte vise aos efeitos do texto.

Interpretar o significado de uma obra de arte pressupõe entender seu comportamento com a verdade. O teórico ainda enfatiza que é característico dos textos literários que não percam sua capacidade de comunicação depois que seu tempo passou; muitos deles ainda conseguem "falar" mesmo depois que sua "mensagem" se tornou histórica e sua "significação" se trivializou.

Conforme o estudioso, a obra adquire seu caráter próprio na leitura, pois a obra é o ser constituído do texto na consciência do leitor. Segundo tal teórico:

se o texto ficcional existe graças ao efeito que estimula nas nossas leituras, então deveríamos compreender a significação mais como produto de efeitos experimentados, ou seja, de efeitos atualizados do que como ideias que antecedem a obra e se manifesta nela (ISER, 1999, p. 54).

Desta forma, a estrutura dos textos ficcionais evidencia um aspecto duplo: é ela estrutura verbal e afetiva ao mesmo tempo. Então, pode-se dizer que as obras literárias ativam processo de realização de sentido, em que a participação do leitor é fundamental neste processo para que a qualidade estética se concretize nesta realização de sentido, pois "a interpretação evidencia o potencial do sentido proporcionado pelo texto" (ISER, 1999, p. 54). Em suma, a qualidade dos textos literários se fundamenta na capacidade de produzir algo que eles próprios não são.

$\mathrm{O}$ texto literário oferece determinados papéis aos seus possíveis receptores. $\mathrm{O}$ leitor está inserido no mundo do texto, por isso seu ponto de vista vai se adequar pela 
sequência de imagens, coincidindo com o sentido construído. Nesse sentido, apenas a imaginação é capaz de captar a informação não dada, de modo que a estrutura textual ao estimular uma ordem de imagens se traduz na consciência receptiva do leitor. As estruturas do texto se traduzem nas experiências do leitor através da imaginação.

Segundo Iser (1999) o texto possui uma estrutura complexa que dificulta a projeção das múltiplas representações por parte do leitor. Esse, por sua vez, precisa abandonar ou reajustar suas representações e então, experimentar algo que ainda não se encontra dentro de seu horizonte. Para que a comunicação seja bem-sucedida é preciso que a atividade do leitor seja de alguma maneira controlada pelo texto. Nesse sentido, o teórico afirma que

O não-dito de cenas aparentemente triviais e os lugares vazios do diálogo incentivam o leitor a ocupar as lacunas com suas projeções. Ele é levado para dentro dos acontecimentos e estimulado a imaginar o não dito com o que é significado. [...] Portanto, o processo de comunicação se põe em movimento e se regula não por causa de um código mas mediante a dialética de mostrar e ocultar. $\mathrm{O}$ não dito o estimula os atos de constituição, mas ao mesmo tempo essa produtividade é controlada pelo dito e este por sua vez deve se modificar quando por fim vem à luz aquilo que se referia (ISER, 1999, p. 106).

O texto, por sua vez, forma um sistema desse tipo de combinações. Neste sistema há um lugar para aquele que deve realizar esta combinação. O lugar sistêmico dá espaço às lacunas que não podem ser preenchidas pelo próprio sistema, mas sim, somente pelo leitor. Estas lacunas regulam a formação das representações do leitor, atividade agora empregada sob as condições que o texto estabelece. Porém, neste sistema há outro lugar marcado por várias negações, no qual o texto e o leitor convergem no momento da leitura.

As lacunas ocultam as relações entre as perspectivas de apresentação do texto e assim incorporam o leitor ao texto para que ele coordene as perspectivas. Assim, os lugares vazios propiciam que o leitor aja dentro do texto e tenha sua atividade controlada pelo texto. Iser (1999) também afirma que o leitor se situa por si só em relação ao texto e a assimetria entre texto e leitor estimula a atividade de constituição que recebe uma determinada estrutura devido às lacunas e às negações do texto, ajustando o processo interativo.

Iser (1999) também enuncia que os lugares vazios e as conexões marcam determinadas conexões não-formuladas do texto e é isso que produz a possibilidade de assimetria fundamental entre texto e leitor. O vazio vai sendo preenchido pelas representações do leitor e este experimenta um mundo que não lhe é familiar. Os objetos de representação, ao se modificarem e se acumularem, confluem no eixo temporal. O sentido só emergirá no decurso da leitura, não podendo ser separado da extensão plena da leitura. O teórico segue enfatizando que

Vem à luz o momento produtivo da fantasia uma vez que o ponto de vista em movimento estrutura o tempo do texto em passado, presente e futuro, sendo que essa estruturação não é responsável por memórias esvaziadas ou experiências arbitrárias, pois produz a síntese de todas as fases temporais. Quando os objetos de representação ganham seu 
aspecto temporal na fantasia do leitor, o sentido se forma a partir da modificação temporal das representações (ISER, 1999, p. 77).

Isso significa que o leitor ao entrar em contato com o texto recebe as informações e, a partir disso, cria novas possibilidades de atualização com base no que precisa produzir em relação ao sentido. Iser (1999) também ressalta que com o momento temporal da fantasia, o leitor cria uma modalidade para o sentido que não só permite o seu desenvolvimento mas também sua regulação, ou seja, o sentido, exigência do texto, não se cumpre sem o momento temporal que se atualiza pelo ato da leitura.

Conforme Jorge Larossa (2003), para a leitura ter um papel na formação do sujeito implica saber que as fronteiras entre o real e o imaginário possuem uma história. O estudioso afirma que a experiência de leitura está do lado subjetivo daí, então, a sua associação com a irrealidade, a ficção, delírio, fantasia, etc. Para povos antigos, a imaginação era um meio fundamental para adquirir conhecimento, pois era a mediação entre o sensível e o inteligível, entre a forma e o intelecto, entre o objetivo e o subjetivo, entre o exterior e interior. Um homem que não possuísse imaginação não poderia ter compreensão das coisas.

Peter Hunt (2011), por sua vez, ao desenvolver um estudo sobre o leitor e o sentido, enfatiza que as crianças são leitores em desenvolvimento. O estudioso ainda menciona que as crianças possuem os textos, no sentido de que os significados que produzem são seus e privados. Por isso, a leitura de contos de fadas pode atingir o que há de mais profundo na essência do ser humano. Essas narrativas repletas de seres mágicos permitem o contato com o encantamento, com as emoções. Logo, segundo Bruno Bettelheim:

[...] as estórias de fadas representam, sob forma imaginativa, aquilo em que consiste o processo sadio de desenvolvimento humano, e como os contos tornam tal desenvolvimento atraente para $o$ engajamento da criança nele. Este processo de crescimento começa com a resistência contra os pais e o medo de crescer, e termina quando o jovem encontrou verdadeiramente a si mesmo, conseguiu independência psicológica e maturidade moral [...] (BETTELHEIM, 2002, p. 12).

Com isso, notamos que os contos de fadas sejam os clássicos ou as adaptações que vêm surgindo nos dias de hoje podem representar os anseios pessoais do leitor e fazer com que haja identificação com as situações apresentadas nessas histórias. A leitura de tais obras se torna primordial na vida e, por isso, pode propiciar ao ser humano para o entendimento de si, de suas ações e do mundo.

\section{A Bela Adormecida e Maleficent: discutindo as histórias}

A história A Bela Adormecida "dos Grimm é considerada uma versão reduzida de Sol, Lua e Tália (1636), de Gimbattista Basile, e de A Bela Adormecida no bosque (1697), de Charles Perrault" (TATAR, 2013, p. 110). No entanto, é a versão dos Grimm que perdura e serve de base para o presente trabalho. 
A narrativa apresenta um casal real que deseja muito ter um filho. Inesperadamente, uma rã aparece durante o banho da rainha e comunica que esta terá uma filha. Uma linda menina nasceu e no dia do seu batizado, o rei oferece um grandioso banquete. As fadas também foram convidadas. Porém, como só tinha 12 pratos de ouro, a $13^{\mathrm{a}}$ fada não foi convidada. Tomada pela fúria, esta vai até o batizado e lança uma maldição: ao $15^{\circ}$ dia do seu aniversário, a princesa espetará o dedo numa roca de fiar e morrerá. Mas uma das fadas não havia concedido seu dom à menina, então, amenizou o feitiço enunciando que a princesa não morreria, apenas adormeceria por cem anos.

A princesa cresceu e todos os desejos proferidos pelas feiticeiras se realizaram. No dia do aniversário de 15 anos da princesa, o rei e a rainha saíram do castelo e deixaram a jovem sozinha. Vagando pela casa, a princesa acabou chegando ao pé de uma velha torre. Ao subir pela estreita escada em forma de caracol, se deparou com uma portinha e ao abri-la encontrou uma velha senhora a fiar linho. $\mathrm{Na}$ medida em que questionou a mulher sobre o que estava "bamboleando assim tão esquisito", a princesa tocou a ponta do fuso com o dedo e caiu em um sono profundo. Neste momento, todos adormecem junto com a princesa:

O rei e a rainha, que acabavam de voltar para casa e estavam entrando no grande salão, adormeceram, e com eles toda a corte. Os cavalos nos estábulos, os cães no quintal, os pombos no telhado e as moscas na parede. Até o fogo que crepitava na lareira morreu e adormeceu. $\mathrm{O}$ assado parou de chiar, e o cozinheiro, que estava a ponto de puxar o cabelo do auxiliar de cozinha porque ele fizera uma tolice, deixou-o escapar e adormeceu. $\mathrm{O}$ vento também amainou, e nem mais uma folha balançou nas árvores fora do castelo (GRIMM; GRIMM, 2013, p. 114-115).

Em torno do castelo cresceram urzes que, a cada ano, ficavam mais altas. Seguindo a lenda sobre a bela Rosa da Urze, muitos príncipes tentaram entrar no castelo, mas acabaram morrendo. Passados muitos anos, no dia do feitiço acabar, um príncipe se dirige até o castelo e encontra no lugar dos espinheiros grandes e lindas flores que o deixaram passar e, após isso, fecharam-se atrás dele. O príncipe se deparou com todos habitantes do castelo em sono profundo. Adentrando pelos cômodos do palácio encontra a bela Rosa da Urze adormecida, com um beijo, a jovem princesa abre finalmente os olhos. Todo o reino também desperta, o príncipe e a princesa se casaram numa festa com grande esplendor e vivem felizes para sempre.

O cenário inicial de Maleficent ${ }^{l}$ apresenta a personagem Malévola, a fada mais poderosa do mundo Moor, sempre bondosa e atenciosa com todos. Ao contrário da narrativa tradicional, a narração fílmica ocorre sob o ponto de vista da antagonista, Malévola que se apaixona por um humano, Stefan. Mas as diferenças entre ambos são fortes o suficiente para separá-los e apresentar a personagem um sentimento, nunca, antes, por ela experimentado: a maldade.

Ao ter suas asas cortadas pela ambição de Stefan em se tornar rei, Malévola percebe que a entrega do seu amor e confiança a um ser que não pertence ao seu mundo, tem um preço a ser pago. Acontece com Malévola, exatamente, o que ocorre com algumas princesas das histórias tradicionais. Quando perde suas asas, a antagonista

\footnotetext{
${ }^{1}$ Maleficent será o termo utilizado para designar o filme e Malévola para a personagem.
} 
passa por um momento de transição, ou seja, ocorre a passagem da adolescência para o mundo adulto, representado, no filme, pelo sofrimento e algumas perdas. Sobre o ritual de passagem dos contos de fadas, Diana e Mário Corso enunciam que:

Fazendo uma comparação, apesar de não haver regras gerais nos rituais de passagem primitivos, podemos afirmar que quase todos fazem alusão a uma morte e a uma ressurreição num novo estágio, às vezes com outro nome (aqui também é o caso, embora só saibamos o seu nome da fase de transição). Esses contos podem ser tanto o resto desses rituais, quanto podem ilustrar alegoricamente o processo de saída da infância para outra modalidade de existência (CORSO; CORSO, 2005, p. 97).

Malévola é traída com um beijo que recebe de Stefan aos dezesseis anos, auge da sua vida adolescente. Segundo ele, era um beijo de amor verdadeiro. Nesse momento, a personagem vive uma fase de encantamento por seu amado que se desconstrói ao ter sua virtude violada quando perde suas asas. A partir disso, Malévola, dominada pela tristeza, torna-se uma fada má, não acredita mais em amor verdadeiro e inicia um reinado de sombras no brejo mágico.

Ao saber do nascimento de Aurora, filha de Stefan e da rainha, através de seu fiel escudeiro, Diaval, Malévola vai até o castelo no dia do batizado da menina e lança um feitiço irrevogável sobre o bebê: Aurora crescerá bela, mas ao entardecer dos seus dezesseis anos espetará o dedo em um fuso de tear e cairá no sono da morte. A idade em que o feitiço se concretizará é o mesmo em que Malévola conheceu a maldade. Isso mostra que um novo ciclo se iniciará na vida da antagonista, pois a partir deste feitiço voltará a acreditar no amor verdadeiro através da convivência com a princesa.

Ao realizar tal ato, Malévola assume o papel de mulher traída, afinal de contas Aurora é a filha de seu antigo amor. Segundo Diana e Mário Corso:

No conto da Bela Adormecida, a velha fada, com seu mau humor invejoso e nocivo, exemplifica o que resta de uma mulher quando a juventude a abandona. Os atrativos femininos seriam uma arma privilegiada de conquista de posição para uma mulher, como o envelhecimento a privaria destes, a mulher necessitaria recorrer a outros feitiços, os da bruxa. (CORSO; CORSO, 2005, p. 76).

Malévola envelhece psicologicamente quando perde a capacidade de acreditar no amor verdadeiro em seu coração, depois da traição de Stefan. Por causa disso, o feitiço surge como uma retaliação pelas asas perdidas. Com isso, a jornada psicológica da reconstrução da identidade de Malévola começa a se reestruturar quando acompanha o crescimento de Aurora. As três fadas que ficaram incumbidas de cuidarem e protegerem a princesa se revelam muito irresponsáveis. Elas assumem o papel de tias desastradas e com isso, Malévola resolve acompanhar de perto a trajetória da menina que amaldiçoou, assumindo o papel de madrinha.

Durante a convivência, a antagonista começa a se afeiçoar pela menina e quando esta completa 15 anos, conhece Malévola e diz que ela é sua fada madrinha. Malévola leva Aurora para viver no mundo dos Moors e a princesa se fascina por este lugar encantado. Aurora vive em harmonia com os habitantes Mor e nele conhece um príncipe que está a caminho do castelo de Stefan. Com o passar do tempo Malévola tenta reverter 
o feitiço que pesa sobre Aurora, mas fracassa. É então, que Aurora decide que quer viver ao lado da madrinha no brejo mágico e visita as três fadas madrinhas para comunicar sua decisão.

Com essa visita, Aurora fica sabendo de tudo o que aconteceu no dia de seu batizado. A princesa vai até o seu destino, pois entra no palácio e encontra a sala onde estão todos os teares. Então, a maldição se cumpre: a princesa cai no sono da morte e somente um beijo de amor verdadeiro pode revertê-lo.

Arrependida do seu ato, Malévola leva, mesmo que inconsciente, o príncipe Philip ao encontro de Aurora para quebrar o feitiço. Percebe-se que o príncipe não sabe nem o caminho do castelo e é a antagonista que o faz adormecer, levando-o até a princesa. Com isso, é possível notar que Philip não é a representação de um homem perfeito e valente, em que a salvação depende de sua coragem, como mostram os contos de fadas. No filme, o príncipe "se perde no caminho" e mostra ser uma personagem fraca e submissa. Philip beija a princesa, mas o feitiço não se rompe. Muito triste, Malévola suplica perdão e promete velar o sono de Aurora para sempre e ao terminar de proferir tais palavras, beija a testa da afilhada como sinal de sua redenção. Neste momento ocorre a magia: Aurora desperta do sono da morte, porque o beijo materno de Malévola representa o amor verdadeiro.

Unidas pelo afeto, é com a ajuda da princesa que Malévola consegue vencer a armadilha que Stefan preparou para ela, ao saber que a fada estava no castelo. Com seus poderes limitados ao ser presa por uma rede de ferro, Aurora encontra as asas da madrinha e as liberta. Retomada sua condição anterior, Malévola, numa luta difícil, consegue derrotar Stefan.

Com a morte do rei e a convivência pacífica entre a princesa e o mundo Moor, além da amizade entre madrinha e afilhada, os reinos são unificados. Aurora é coroada rainha por Malévola e com isso, reina a harmonia, não mais a ganância.

Através da apresentação dos enredos do conto de fadas A Bela Adormecida e do filme Maleficent podemos perceber que "analisar e refletir sobre suas variáveis também faz parte desse processo, joga luz sobre elas, aponta caminhos, ilumina trilhas e revigora esse caudal inesgotável, sempre pronto a surpreender o leitor c/////om novas possibilidades de releitura" (RICHE, 2015, p. 7).

\section{Uma estratégia de leitura ${ }^{2}$ de A Bela Adormecida e Maleficent}

\section{$1^{\text {a }}$ Etapa}

1. O professor mediador deverá fixar nas mesas de cada aluno uma imagem ${ }^{3}$ do conto de fadas A Bela Adormecida. Eles devem olhar, ler, trocar com o colega e dialogar sobre o significado de cada imagem/texto. Depois, no grande grupo, escolhem sobre qual delas gostariam de falar.

\footnotetext{
${ }^{2}$ Espera-se que os alunos já tenham estudado a estrutura da narrativa. Por isso, é aconselhável que tal atividade seja aplicada para $5^{\circ}, 6^{\circ}$ ou $7^{\circ}$ ano.

${ }^{3}$ Tais imagens são sugestões e foram retiradas do livro Contos de Fadas: edição comentada e ilustrada, de Maria Tatar. Coloquei nos espaçamento 1,0.
} 
Revista Leia Escola, Campina Grande, v. 19, n. 2, 2019 - ISSN 2358-5870

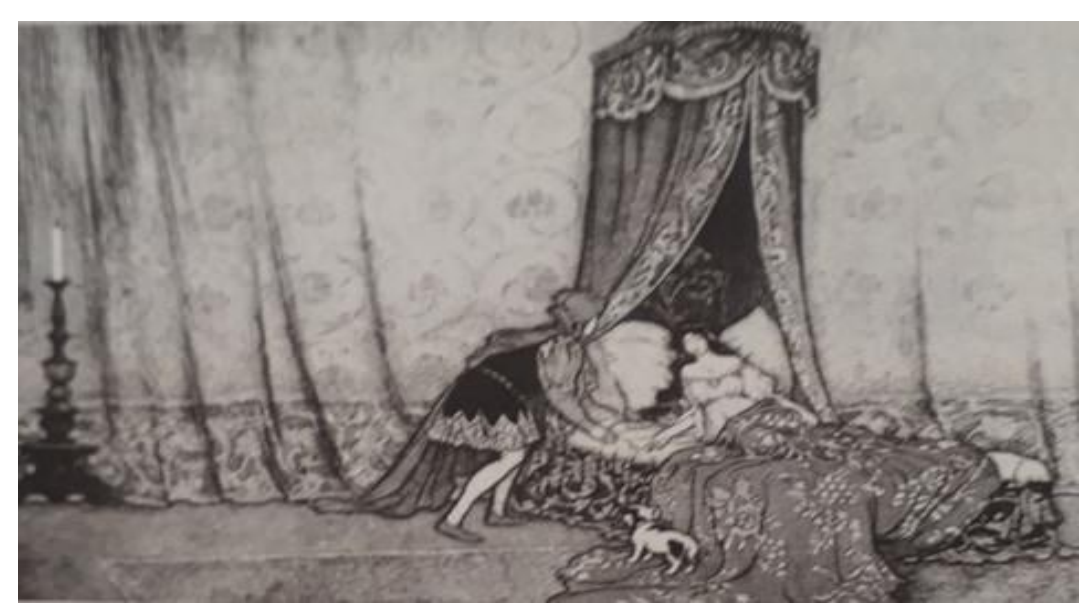

Warwick Goble, 1923

Figura 2

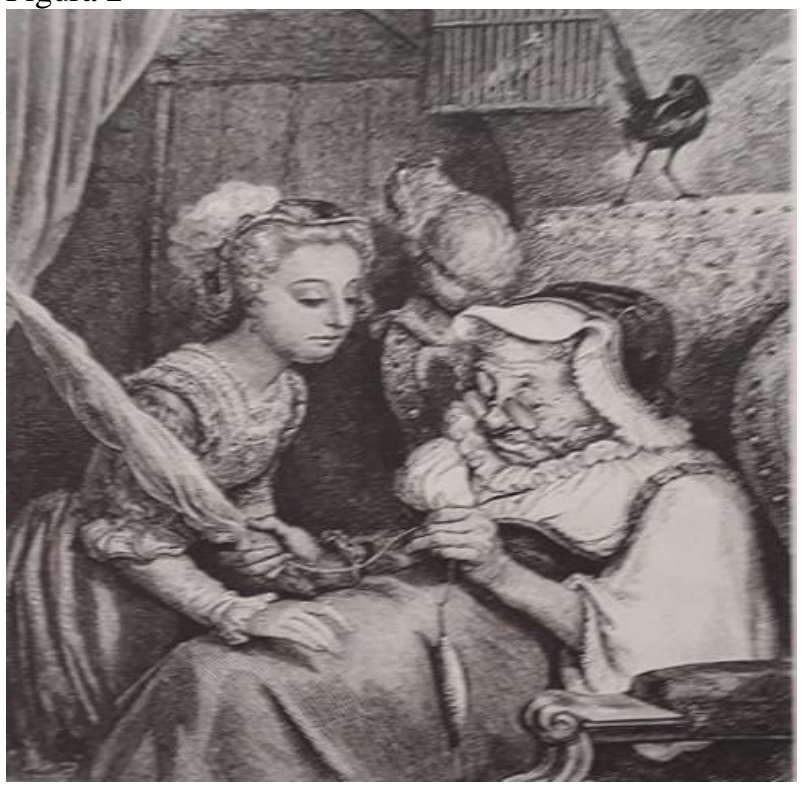

Gustave Doré, 1861

Figura 3

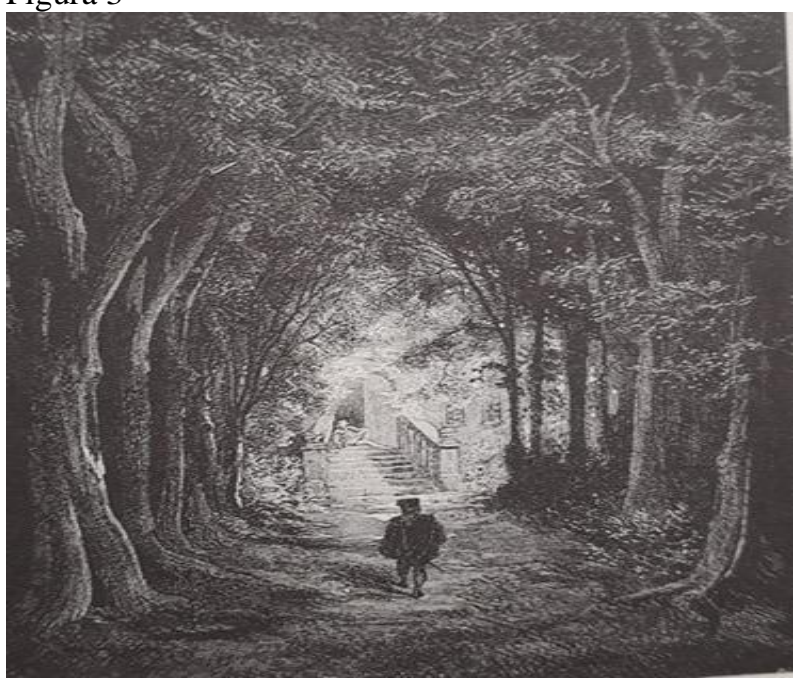

Gustave Doré, 1861

Figura 4 


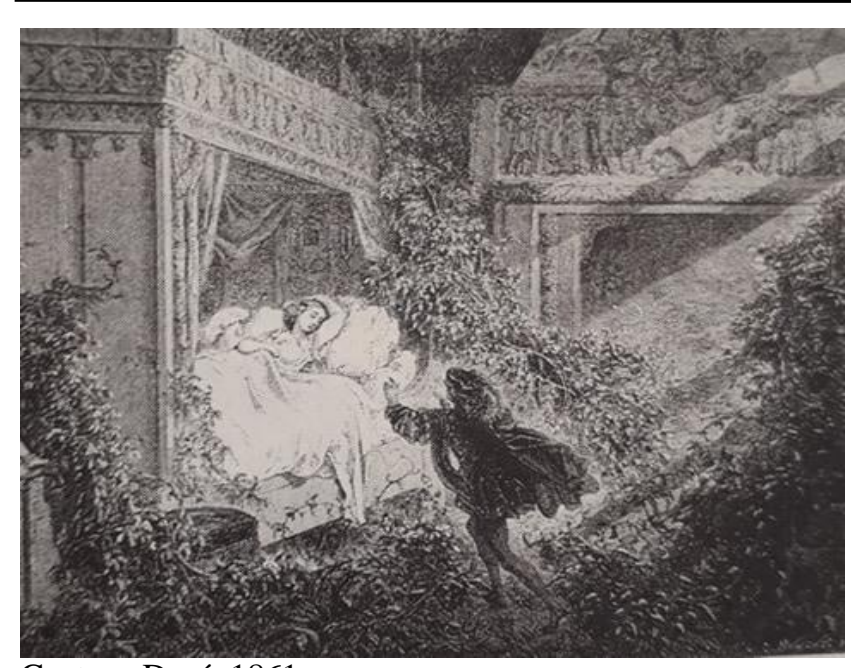

Gustave Doré, 1861

\section{Figura 5}

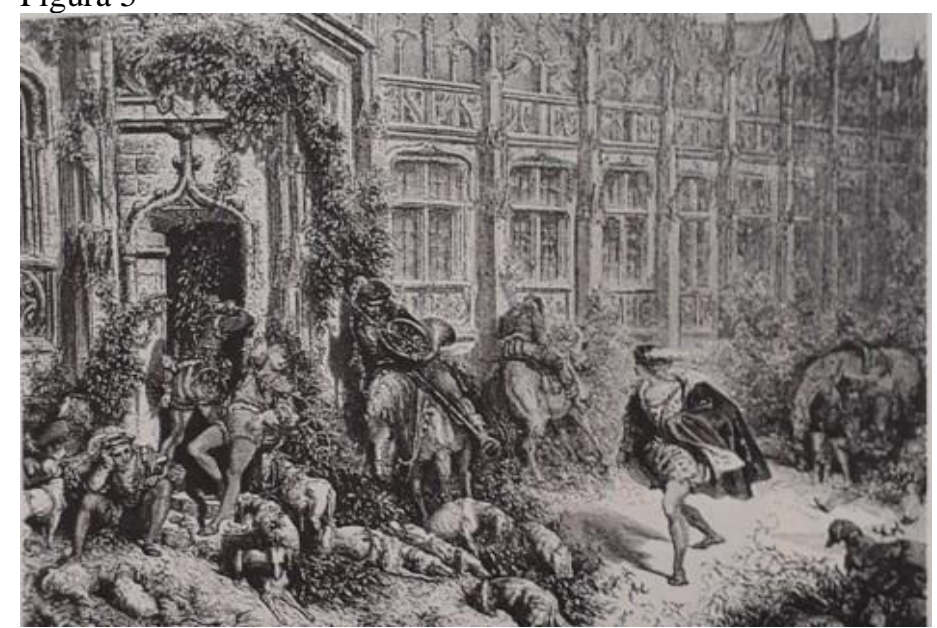

Gustave Doré, 1861

Figura 6

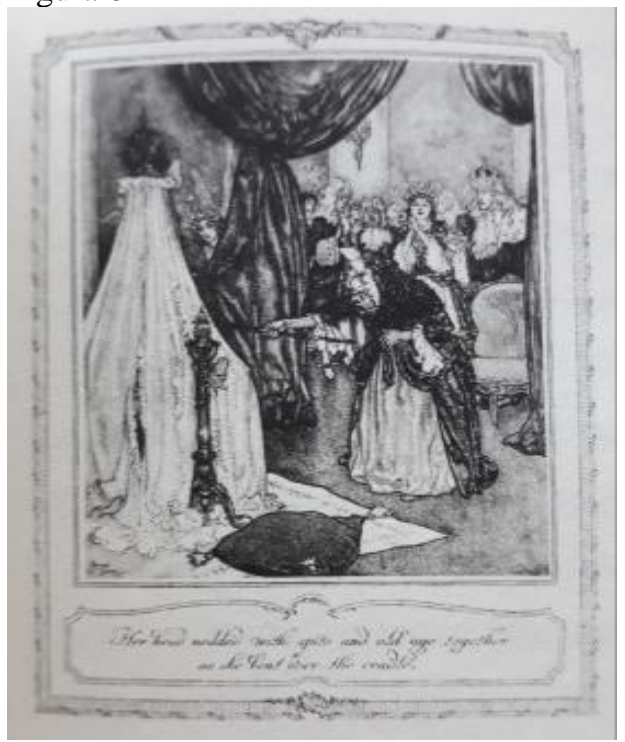

Edmund Dulac, 1912 
2. O professor mediador deverá questionar os alunos sobre qual história é representada nas imagens.

3. Propor que, em grupo de 5 pessoas, os alunos realizem a leitura do conto de fadas $A$ Bela Adormecida, dos Irmãos Grimm em que cada um terá uma função na equipe:

- Facilitador: quem fará a leitura da história;

- Repórter: responsável pelo registro das considerações do grupo;

- Monitor: aquele que deve pesquisar mais informações sobre a narrativa: características das personagens, adaptações da história, vida dos autores, etc.

Observação: os alunos podem utilizar o celular para pesquisar na internet;

- Harmonizador: responsável por fiscalizar o desenvolvimento da atividade;

- Controlador do tempo: quem deverá cronometrar o tempo estipulado pelo professor mediador.

\section{$2^{\text {a }}$ Etapa}

1. Perguntar quais filmes de A Bela Adormecida os alunos conhecem.

2. Apresentar as imagens dos filmes numa tela projetada.

3. Assistir ao filme Maleficent.

4. O professor mediador deverá fazer uma comparação entre o conto de fadas tradicional e o filme.

5. Questionar sobre as semelhanças e diferenças entre ambas as narrativas.

\section{$3^{\text {a }}$ Etapa}

1. Dividir os alunos em grupos.

2. Propor a dinâmica Debate com base nas seguintes perguntas norteadoras: As atitudes da protagonista pode representar ações dos seres humanos? De que forma? Conhecem ou já viveram alguma situação semelhante?

3. O grupo deve se reunir para conversar sobre as questões.

4. Cada secretário deverá sumarizar as conclusões da equipe no quadro negro.

5. Os debatedores fazem suas arguições.

6. O professor mediador deverá encerrar as discussões mencionando as temáticas que se encontram no filme.

\section{$4^{\text {a }}$ Etapa}

1. Solicitar que cada aluno crie uma personagem própria, ou seja, não pode ser uma figura ficcional já existente em contos de fadas, filmes, etc. A personagem deve possuir um nome.

2. Os estudantes devem vir caracterizados e socializar para a turma como construíram tal personagem e descrever suas características.

3. Realizar o registro iconográfico das caracterizações e propor a criação de um blog da turma para realizar as postagens das fotos ${ }^{4}$. Nesse espaço virtual, também poderão ser divulgados sugestões de textos literários e filmes além de outras atividades da turma.

\section{Considerações finais}

O intuito em desenvolver este trabalho se deu em prol da relevância que os contos de fadas clássicos e as novas roupagens que essas histórias estão ganhando nos dias de hoje, através de produções cinematográficas e a relação que possuem com a formação de leitores. Por isso, a apresentação de uma estratégia de leitura a partir do

\footnotetext{
${ }^{4} \mathrm{O}$ uso das imagens dos alunos deve apresentar autorização dos responsáveis.
} 
conto de fadas A Bela Adormecida e o filme Maleficent objetiva evidenciar que tais narrativas trazem temas relevantes para a discussão e formação do pensamento crítico do sujeito.

A versão para o cinema da história que não foi contada pelo conto tradicional, além de evidenciar o leitor como participante ativo no processo de significação do texto, mostra novas características as quais, muitas vezes, se encontram na personalidade desses receptores: pessoas com crises existenciais, problemas familiares, sentimentais, entre tantos outros que podemos identificar se analisarmos os demais contos de fadas existentes.

Portanto, a abordagem teórica, a apresentação do conto e do filme bem como a proposta de estratégia de leitura apresentada neste texto mostra que o desenvolvimento de ações metodológicas que possibilitam o trabalho com essas histórias clássicas e suas adaptações contemporâneas se faz relevante para auxiliar os sujeitos na compreensão de si e do mundo e, principalmente, a partir disso, tornarem-se cidadãos críticos.

\section{Referências}

BETTELHEIM, B. A psicanálise dos contos de fadas. 8.ed. Rio de Janeiro: Paz e Terra, 1980.

CORSO, D.; CORSO, M. Fadas no divã: psicanálise nas histórias infantis. Porto Alegre: Artmed, 2005.

- Mãelévola. Disponível em: [http://www.marioedianacorso.com/maelevola]. Acesso em 10. Jul. 2014.

GRIMM, J; GRIMM, W. A Bela Adormecida. In: TATAR, M. Contos de fadas: edição comentada e ilustrada. Trad. Maria Luiza X. de A. Borges. Rio de Janeiro: Zahar, 2013.

HUNT, P. Crítica, Teoria e Literatura Infantil. Trad. Cid Knipel. São Paulo: Cosac Naify, 2010.

ISER, W. $O$ ato da leitura: uma teoria do efeito estético. Trad. Johannes Kretschemer. São Paulo: Editora 34, 1999b, v.2.

LAROSSA, J. La experiência de la lectura. México: FCE, 2003.

MALÉVOLA (MALEFICENT). Direção de Robert Stromberg. Produção de Joe Roth. Roteiro de Linda Woolverton. EUA: Walt Disney Pictures, 2014. (97 min).

RICHE, R. M. Prefácio. In: DEBUS, E.; MICHELLI, R. (Orgs.). Entre fadas e bruxas: o mundo feérico dos contos para crianças e jovens. Rio de Janeiro: Dialogarts, 2015. p.6-7.

Recebido em 20 de junho de 2019

Aceito em 07 de agosto de 2019 